\title{
Shock séptico asociado a gangrena gaseosa - Miositis necrotizante por Clostridium.
}

\author{
DOI: http//dx.doi.org/10.37315/SOTOCAV202028455136 \\ CRIADO-ALBILLOS G, MARTíN-RODRÍGUEZ ADP, MENDIETA-DIAZ L, MILLÁN CID M, DELGADO-GONZÁLEZ A. \\ COMPLEJO ASISTENCIAL UNIVERSITARIO DE BURGOS
}

\begin{abstract}
Resumen.
Introducción: La gangrena gaseosa, también llamada miositis necrotizante o mionecrosis por Clostridium es una infección muscular y de tejidos blandos aguda potencialmente mortal, causada por patógenos del género Clostridium. Caso clínico: Presentamos el caso de una gangrena gaseosa espontánea por C. Perfringens en un paciente sin antecedente traumático. Discusión: El tratamiento de la gangrena gaseosa consiste en un temprano desbridamiento quirúrgico junto a antibioterapia. Especialmente importante es el desbridamiento quirúrgico urgente si se pretende lograr la supervivencia del paciente, preservar la extremidad y prevenir complicaciones. En caso de obtener confirmación de C. Perfringens la antibioterapia debería consistir en Penicilina (3-4 millones de unidades intravenoso cada 4h) más Clindamicina (900 mg intravenoso cada 8) o bien Tetraciclina (500 mg intravenoso cada 6h). A pesar de encontrarnos a un paciente sin antecedente traumático, sin patología gastrointestinal, neutropenia o inmunodeficiencias debemos sospechar este diagnóstico rápidamente ante la presencia de un dolor exagerado de una extremidad con o sin fiebre. Es importante esta sospecha debido a la necesidad de un tratamiento rápido y agresivo para salvar el miembro, la vida del paciente y prevenir complicaciones.
\end{abstract}

Palabras clave: gangrena gaseosa, miositis necrotizante, Clostridium, shock séptico, anaerobio, infección de partes blandas.

\section{Summary.}

Introduction: Gas gangrene, also known as clostridial myonecrosis, is an acute, potentially life-threatening infection of muscular and soft tissues caused by pathogens in the Clostridium genus. Clinical case: We present the case of spontaneous gas gangrene caused by $\mathrm{C}$. Perfringens in a patient with no history of trauma. Discussion: The treatment of gas gangrene consists of prompt surgical debridement combined with antibiotic therapy. Emergency surgical debridement is especially important for patient survival, preserving the limb and preventing complications. If $\mathrm{C}$. Perfringens is confirmed, the antibiotic therapy should consist of penicillin (3-4 million units intravenously every $4 \mathrm{~h}$ ) with clindamycin ( 900 $\mathrm{mg}$ intravenously every $8 \mathrm{~h}$ ) or tetracycline (500 mg intravenously every $6 \mathrm{~h}$ ). Even when we encounter a patient with no history of trauma, gastrointestinal pathology, neutropenia or immunodeficiencies, we should quickly suspect this diagnosis when there is extreme pain in a limb, with or without fever. This suspicion is important due to the need for rapid and aggressive treatment to save the limb and life of the patient and to prevent complications.

\author{
Correspondencia: \\ Correspondencia: \\ Guillermo Criado Albillos \\ guillecrial@hotmail.com
}




\section{Introducción}

La gangrena gaseosa, también llamada miositis necrotizante o mionecrosis por Clostridium es una infección muscular y de tejidos blandos aguda potencialmente mortal causada por patógenos del género Clostridium ${ }^{1}$. Históricamente su conocimiento se debe a su frecuente aparición en heridas de guerra especialmente en la $1^{\mathrm{a}}$ y $2^{\mathrm{a}}$ Guerra Mundial. Hay dos formas de presentación bien definidas: traumáticas o espontáneas.

Traumáticas: las heridas con compromiso avascular (especialmente heridas penetrantes de cuchillos, tiros de escopetas o aplastamientos) crean un ambiente anaerobio ideal para la proliferación de Clostridium. Son el $70-80 \%$ aproximadamente de los casos de gangrena gaseosa. El germen más frecuente es el C. Perfringens ${ }^{2}$.

- Atraumáticas o espontáneas: generalmente su diseminación es por vía hematógena con siembra del germen en el tejido muscular. La puerta de entrada suele ser el tracto digestivo (lesiones gastrointestinales, adenocarcinomas de colon) y se asocia con frecuencia a paciente neutropénicos. El patógeno más frecuente es $C$. Septicum

\section{Caso clínico}

Paciente de 64 años, sin alergias, con hipertensión arterial (HTA) y Diabetes Mellitus II bien controlada con Metformina $850 \mathrm{mg}$ como antecedentes personales. Portador de una prótesis total en la cadera derecha implantada en 2014.

El paciente acude a su hospital comarcal de referencia por intenso dolor a nivel de cadera izquierda de $72 \mathrm{~h}$ de evolución, sin fiebre asociada. El paciente y la familia cuentan dolor leve durante el mes previo en dicha cadera sin incapacidad funcional hasta ese momento.

Dada la clínica en el momento de la valoración se decide su ingreso en el servicio de Cirugía Ortopédica y Traumatología, donde se recogen hemocultivos y se pauta analgesia convencional sin conseguir un óptimo control del dolor durante estos días.
Al tercer día de ingreso hospitalario comienza con malestar general, taquicardia y sudoración profusa, así como hipotensión marcada. Se realiza analítica convencional en la que destaca fallo multiorgánico con acidosis metabólica, fallo renal agudo, coagulopatía, plaquetopenia y fallo hemodinámico, motivo por el que se decide el traslado del paciente a un centro hospitalario de 3er nivel de referencia para valoración y filiación del cuadro instaurado.

Previo al traslado se administra antibioterapia (2 gramos de Cefotaxima), bicarbonato y amiodarona por una Fibrilación Auricular (FA) de nueva aparición.

A su llegada al centro de referencia el paciente se encuentra hemodinámicamente inestable, con TAS en torno a $80 \mathrm{mmHg}$, FA rápida y un índice Glasgow Coma Scale (GCS) de 6.

La inestabilidad hemodinámica obliga a iniciar desde el primer momento de la llegada del paciente a este centro dosis altas de noradrenalina y sueroterapia intensiva. A pesar de esto, es necesario proceder a intubación orotraqueal y canalización de catéter arterial radial y catéter venoso central yugular para iniciar el tratamiento de la acidosis metabólica franca. Igualmente, se continua con antibioterapia de amplio espectro (Meropenem y Linezolid), sospechando como foco del shock séptico la cadera izquierda.

En una primera exploración del miembro afectado, realizada con el paciente intubado y sedado, únicamente se puede destacar la presencia de crepitación en la cara más proximal e interna del muslo, sin eritema, tumefacción, cambios de color, aumentos de temperatura o cualquier otro signo clínico.

Dada la sospecha inicial, se decide realizar Tomografía Computerizada (TC) abdominopélvico (Fig. 1), en el que se observan múltiples burbujas de aire a nivel de la raíz del muslo izquierdo que diseca planos fasciales con extensión principalmente anteromedial entre la musculatura abductora y cuádriceps, en el espesor del glúteo menor izquierdo y rodeando la porción ilíaca del psoas y en la medular de los huesos de la hemipelvis izquierda y fémur, con discretas alteraciones de la densidad intramedular.

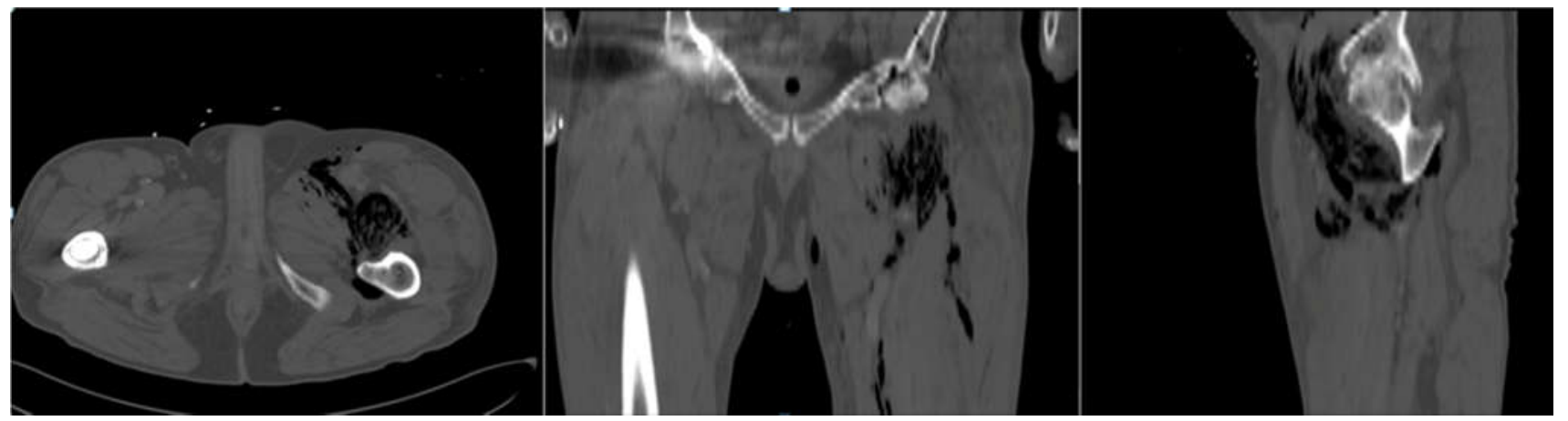

Figura 1: Cortes TC Axial, coronal y sagital del paciente. 
Igualmente, presencia de aire en el interior de la articulación coxofemoral izquierda.

Analizadas las pruebas complementarias y dada la falta de respuesta del paciente al tratamiento instaurado hasta el momento se decide intervención quirúrgica urgente a pesar de carecer de un diagnóstico claro.

Con el paciente en decúbito supino, se procede a un abordaje anterolateral de la cadera y muslo proximal izquierdos. Intraoperatoriamente, la piel y el tejido subcutáneo son normales en todos los aspectos, pero conforme se profundiza se observa que la fascia no presenta tensión y los tejidos blandos presentan un aspecto desvitalizado y decolorado, sin alteraciones claras en su consistencia, pero con mínimo sangrado. En planos más profundos surge un contenido edematoso serohemorrágico sin apariencia purulenta, pero de olor fétido, y una intensa disección gaseosa a nivel de la musculatura proximal de muslo. Se encuentran disecados por gas los trayectos de los músculos Psoas-ilíaco, sartorio y cuádriceps-recto anterior, correspondiéndose con las imágenes observadas en la TC. Ante estos hallazgos se realiza un desbridamiento intenso del tejido macroscópicamente afectado añadido a un profuso lavado y toma de muestras en distintas localizaciones.

Tras la intervención quirúrgica el paciente continúa en acidosis metabólica refractaria a pesar del tratamiento con bicarbonato y sueroterapia intensa. Seguidamente, presenta fallo multiorgánico que deriva en parada cardiorrespiratoria necesitando maniobras de reanimación avanzada.

Finalmente, y a pesar de todas las medidas instauradas, no se consigue revertir el fallo multiorgánico y la acidosis refractarios a todo tipo de tratamiento instaurado y nueva parada cardiorrespiratoria, falleciendo el paciente $3 \mathrm{~h}$ después de su salida de quirófano y a las 9 h después de su llegada al centro hospitalario de referencia.

\section{Discusión}

La gangrena gaseosa o miositis necrotizante es una infección musculoesquelética fulminante originada por las toxinas del género Clostridium, productoras de gas en el músculo, no en el tejido subcutáneo ${ }^{3}$. Históricamente esta patología ha ido de la mano de heridas de guerra, sin embargo, en la actualidad es más frecuente en heridas traumáticas o quirúrgicas.

Las especies más comunes son C. Perfringens y C. Septicum. Algunos factores predisponentes del huésped incluyen carcinomas del tracto digestivo, enfermedades linfoproliferativas, quimioterapia, síndrome de inmunodeficiencia adquirida o estados neutropénicos.

La mayoría de los casos descritos de gangrena gaseosa espontánea han sido causados por C. Septicum y generalmente asociados a estados predisponentes del huésped anteriormente descritos.
La clínica es consecuencia de la producción por las especies Clostridium de exotoxinas capaces de destruir y hemolizar el tejido conectivo y bloquear la agregación plaquetaria sin una respuesta inflamatoria significativa ${ }^{4}$. Igualmente, estas toxinas pueden producir sistémicamente hipotensión y disminución de la contractibilidad cardiaca ${ }^{4-5}$ y fallo renal y multiorgánico.

La gangrena gaseosa espontánea suele debutar como dolor severo e intenso allá donde esté actuando el patógeno, sin fiebre ni alteraciones hemodinámicas, que, sí aparecen tardíamente. No obstante, está descrito que las primeras manifestaciones clínicas puedan ser confusión o malestar $^{2,6}$. La crepitación suele ser un signo tardío. Acostumbra a evolucionar rápidamente con edema serohemorrágico en la región tisular afectada. La piel, si bien en estadios iniciales no muestra alteraciones, posteriormente puede presentar vesículas y ampollas, ligado al rápido inicio de la clínica sistémica.

El diagnóstico precisa de una alta sospecha clínica cuando se presente un paciente con fiebre e intenso dolor de una extremidad en ausencia de antecedente traumático junto a la presencia de gas en tejidos blandos observado en radiografías, tomografías 0 imágenes de Resonancia magnética.

El diagnóstico definitivo de necrosis gaseosa espontánea requiere de la presencia de patógenos Gram+ en racimo en el sitio de la lesión, siendo de ayuda la presencia de los mismos patógenos en hemocultivos. De hecho, la presencia de una bacteriemia por Clostridium suele preceder al resto de la clínica en varias horas.

Durante la intervención quirúrgica es frecuente encontrar tejido muscular que no sangra o arreactivo y observar el propio tejido edematoso y decolorado.

El tratamiento de la gangrena gaseosa consiste en un temprano desbridamiento quirúrgico junto a antibioterapia ${ }^{7}$. Especialmente importante es el desbridamiento quirúrgico urgente si se pretende lograr la supervivencia del paciente, preservar la extremidad y prevenir complicaciones ${ }^{8}$. Es frecuente la necesidad de posteriores desbridamientos.

Hasta el diagnóstico etiológico definitivo se debe administrar tratamiento antibiótico empírico de amplio espectro que cubra Streptococcus grupo A, Clostridium e infecciones mixtas (Aerobias y anaerobias). Para ello se aconseja Piperacilina-Tazobactam $(4.5 \mathrm{mg}$ cada $8 \mathrm{~h}$ intravenoso) más Clindamicina (900 mg intravenoso cada $8 \mathrm{~h})^{7}$

Obtenida la confirmación etiológica por C. Perfringens la antibioterapia debería consistir en Penicilina (3-4 millones de unidades intravenoso cada $4 \mathrm{~h}$ ) más Clindamicina (900 $\mathrm{mg}$ intravenoso cada $8 \mathrm{~h}$ ) o bien Tetraciclina $(500 \mathrm{mg}$ intravenoso cada $6 \mathrm{~h})^{8}$. En pacientes alérgicos a Penicilina se deberá usar Clindamicina en monoterapia. Esta antibioterapia es extrapolable para el tratamiento de la gangrena gaseosa por C. Septicum. 
El uso de Oxígeno hiperbárico en el tratamiento de la gangrena gaseosa es controvertido. Algunos estudios describen buenos resultados en el uso combinado de Desbridamiento, antibioterapia y oxígeno hiperbárico ${ }^{9}$, sin embargo los pacientes con inestabilidad hemodinámica no son candidatos a este tratamiento, y en ningún caso dicho tratamiento deberá retrasar el desbridamiento quirúrgico.

Aquellos pacientes que sobrevivan a la gangrena gaseosa atraumática deberán realizarse una colonoscopia en busca de posible patología abdominal.

El pronóstico a día de hoy continúa siendo malo con una mortalidad de entre el 67 y el $100 \%$ según las series ${ }^{10}$. La mayoría de las muertes ocurren en las primeras $24 \mathrm{~h}$ desde el inicio del cuadro. Los pacientes inmunodeprimidos o con patologías tumorales tienen peor pronóstico.

Se ha presentado un caso de necrosis gaseosa espontánea en un paciente sin patología previa, ni traumática ni digestiva.
A pesar de que este tipo de necrosis está frecuentemente causado por C. Septicum, en nuestro caso el patógeno aislado fue C. Perfringens en contra de la literatura existente. Si bien el resto del cuadro fue congruente con otros datos publicados, debemos sospechar que una gangrena gaseosa no traumática pueda estar causado por C. Perfringens, aunque independientemente de la especie de Clostridium implicada en el cuadro el tratamiento definitivo y el pronóstico son los mismos.

Por lo tanto, a pesar de encontrarnos a un paciente sin antecedente traumático, sin patología gastrointestinal, neutropenia o inmunodeficiencias debemos pensar en este diagnóstico ante la presencia de un dolor exagerado de una extremidad con o sin fiebre. Es importante esta sospecha debido a la necesidad de un tratamiento rápido y agresivo consistente en desbridamiento urgente más antibioterapia intensa para salvar el miembro, la vida del paciente y prevenir complicaciones.

\section{Bibliografía}

1. Buboltz JB, Murphy-Lavoie HM. Gas Gangrene. En: StatPearls [Internet]. Treasure Island (FL): StatPearls Publishing; 2020 [citado 26 de marzo de 2020]. Disponible en: http://www.ncbi.nlm.nih.gov/books/NBK537030/

2. Awad MM, Bryant AE, Stevens DL, Rood JI. Virulence studies on chromosomal alpha-toxin and theta-toxin mutants constructed by allelic exchange provide genetic evidence for the essential role of alpha-toxin in Clostridium perfringens-mediated gas gangrene. Mol Microbiol 1995; 15(2):191-202.

3. Chapnick EK, Abter EI. NECROTIZING SOFT-TISSUE INFECTIONS. Infectious Disease Clinics of North America 1996; 10(4):835-55.

4. Cline KA, Turnbull TL. Clostridial myonecrosis. Annals of Emergency Medicine 1985;14(5):459-66.

5. Asmuth DM, Olson RD, Hackett SP, Bryant AE, Tweten RK, Tso JY, et al. Effects of Clostridium perfringens recombinant and crude phospholipase $C$ and theta-toxin on rabbit hemodynamic parameters. J Infect Dis 1995; 172(5):1317-23.

6. $\quad$ Alpern RJ, Dowell VR. Clostridium septicum infections and malignancy. JAMA 1969; 209(3):385-8.

7. Stevens DL, Bisno AL, Chambers HF, Dellinger EP, Goldstein EJ, Gorbach SL, et al. Practice guidelines for the diagnosis and management of skin and soft tissue infections: 2014 update by the Infectious Diseases Society of America. - PubMed - NCBI [Internet]. [citado 26 de marzo de 2020]. Disponible en: https://pubmed.publicaciones.saludcastillayleon.es/pubmed?term=24973422

8. Mallozzi M. Clostridial myonecrosis - UpToDate [Internet]. [citado 26 de marzo de 2020]. Disponible en: https://uptodate.publicaciones.saludcastillayleon.es/contents/clostridial-

myonecrosis?search=Clostridial\%20myonecrosis\&source=search_result\&selectedTitle=1 150\&usage_type=default

9. Kaide CG, Khandelwal S. Hyperbaric oxygen: applications in infectious disease. - PubMed - NCBI [Internet]. [citado 26 de marzo de 2020]. Disponible en: https://pubmed.publicaciones.saludcastillayleon.es/pubmed?term=18406988

10. Bodey GP, Rodriguez S, Fainstein V, Elting LS. Clostridial bacteremia in cancer patients. A 12-year experience. - PubMed NCBI [Internet]. [citado 26 de marzo de 2020]. Disponible en: https://pubmed.publicaciones.saludcastillayleon.es/pubmed?term=2004306 